14.8

\title{
Предпосевная обработка семян озимой пшеницы поверхностным разрядом
}

\author{
(C) А.В. Лазукин, ${ }^{1,2}$ С.В. Гундарева, ${ }^{2}$ И.А. Моралев, ${ }^{2,3}$ С.А. Кривов ${ }^{2}$ \\ ${ }^{1}$ Институт фоизиологии растений им. К.А. Тимирязева РАН, \\ 127276 Москва, Россия \\ ${ }^{2}$ Национальный исследовательский университет „МЭИ“, \\ 111250 Москва, Россия \\ ${ }^{3}$ Объединенный институт высоких температур РАН, \\ 125412 Москва, Россия \\ e-mail: lazukin_av@mail.ru
}

Поступило в Редакцию 12 декабря 2019 г.

В окончательной редакции 12 декабря 2019 г.

Принято к публикации 17 февраля 2020 г.

\begin{abstract}
Приведены результаты экспериментального исследования действия продуктов поверхностного разряда на семена мягкой озимой пшеницы в электродных конфигурациях, состоящих из параллельных полос с расстоянием между полосами 5 и $10 \mathrm{~mm}$. В каждой из систем семена экспонировались 10, 60, 120 или $180 \mathrm{~s}$ при напряжениях 1.8, 2.1, 2.4 или $2.7 \mathrm{kV}$ при питании электродов синусоидальным напряжением частотой $4.4 \mathrm{kHz}$. Семена располагались в один слой на заземленной плоскости на расстоянии $10 \mathrm{~mm}$ от плоскости диэлектрического барьера. Результаты обработки оценивались по морфологическим характеристикам трехсуточных проростков. Методом трассерной визуализации частиц контролировалось распределение воздушных течений в промежутке. Показано, что режимы обработки разделяются на две принципиальные группы. Первая группа - когда воздушный поток достигает плоскость, на которой располагаются семена, вторая группа - когда воздушный поток не достигает ее. В первом случае (расстояние между полосами $10 \mathrm{~mm}$, напряжение $2.4-2.7 \mathrm{kV}$ при всех экспозициях) удается достичь режимов, стимулирующих прорастание. Всхожесть семян не изменялась и сохраняла высокие значения во всех рассмотренных режимах.
\end{abstract}

Ключевые слова: Поверхностный барьерный разряд, предпосевная подготовка, озимая пшеница, ионный ветер, трассерная визуализация частиц.

DOI: 10.21883/JTF.2020.10.49790.398-19

\section{Введение}

Работы по применению методов физического воздействия на покоящееся семя с целью стимуляции его последующего развития известны давно. Список предлагаемых воздействий широкий. Это действие слабой радиации, СВЧ экспонирование, газоплазменное экспонирование, озонирование, действие света различных длин волн, в том числе лазерного излучения, экспонирование в электрических и магнитных полях, действие импульсного тепла, волн давления, в том числе гидроударов [1-3]. При большом числе вариаций воздействия количество ответов системы (семени), подвергающейся ему, остается ограниченным. Особенности ответа (ускорение развития, повышение всхожести, урожайности, устойчивости) не имеют заметной разницы по интенсивности в зависимости от используемого метода, если он успешно скорректирован (подобрана оптимальная доза воздействия). Таким образом, на первый план выходят другие показатели физических обработок, например, отсутствие расходных материалов на акт обработки, простота перебора режимов, зависимость успешности обработки от сторонних факторов, однородность реакции посевного материала, отсутствие повреждения из- за переэкспонирования, экологичность и безопасность метода.

Под методами „газоплазменного экспонирования“ объединяется использование в предпосевной подготовке дуговых, тлеющих, коронных и барьерных электрических разрядов. Для этого типа воздействия показана полевая эффективность, например, в работе [4], которая опирается на еще более обширное исследование [5], посвященное действию импульсного света на прорастание. В рамках этих исследований существует вывод, что кратковременный импульсный режим воздействия более предпочтителен, чем стационарный.

Поверхностный диэлектрический барьерный разряд (ПДБР) представляет собой незавершенный скользящий разряд атмосферного давления, существующий у электрода с малым радиусом кривизны вблизи поверхности твердого диэлектрика. Разряд существует в виде большого числа кратковременных микроразрядов, отличающихся для положительной и отрицательной полуволны. При питании разряда гармоническим напряжением микроразряды группируются по питающим полуволнам, создавая паузу в горении разряда [6]. Это обеспечивает импульсный режим воздействия без дополнительных ис- 
полнительных средств. Эффективность барьерного разряда в предпосевной подготовке показана в воздухе атмосферного давления для различных семян [7-9].

Известно, что ПДБР во влажном воздухе атмосферного давления имеет разветвленную химию $[10,11]$. Одним из относительно долгоживущих продуктов химических превращений в зоне разряда является озон. Поверхностный разряд используется в различных установках по синтезу озона [12]. Действие озона (изолированно, без внимания к способу получения) рассматривается как отдельный прием предпосевной подготовки [13], для которой понятие эффективной дозы воздействия определяется сочетанием концентрации действующего озона и времени экспозиции. Таким образом, располагая семена в область около электродной системы ПДБР, где концентрация озона выше, можно заметно сократить время экспонирования.

Обстоятельства переноса озона от плоскости диэлектрического барьера, где существует разряд, к слою семян зависит от особенностей распространения воздушных течений, индуцируемых в промежутке ионным ветром. Структура подобного воздушного течения, в свою очередь, зависит от конфигурации электродной системы (в случае системы параллельных полос - от расстояния между полосами) и приложенного к электродной системе напряжения (по амплитуде, частоте и форме) [14].

В настоящей работе исследуется влияние расстояния между электродами в конфигурации ПДБР, состоящей из параллельных полос, на особенности ответа морфологических характеристик проростков мягкой озимой пшеницы, полученных из семян, обработанных при различных напряжениях питания и выдержках, под действием продуктов разряда.

\section{1. Экспериментальная часть}

Обработка выполнялась с помощью двух электродных систем, состоящих из ряда параллельных полос, выполненных из медной фольги и расположенных на поверхности диэлектрического барьера из оксида алюминия толщиной $1 \mathrm{~mm}$ (рис. 1). В одной из систем расстояние между параллельными полосами $5 \mathrm{~mm}$, во второй $10 \mathrm{~mm}$. Напряжение было приложено к полосовым электродам, обратный электрод, занимающий всю площадь диэлектрического барьера, был заземлен. На плоскости обратного электрода были расположены радиаторы охлаждения. На расстоянии $10 \mathrm{~mm}$ от поверхности диэлектрического барьера размещалась металлическая заземленная плоскость. На поверхности этой плоскости в один слой располагались семена.

В качестве модельного объекта использовались высококачественные семена озимой мягкой пшеницы сорта „Иркутская“ урожая 2018 г., полученные из коллекций ЦКП „Биоресурсный центр“ Сибирского института физиологии и биохимии растений СО РАН (Иркутск).

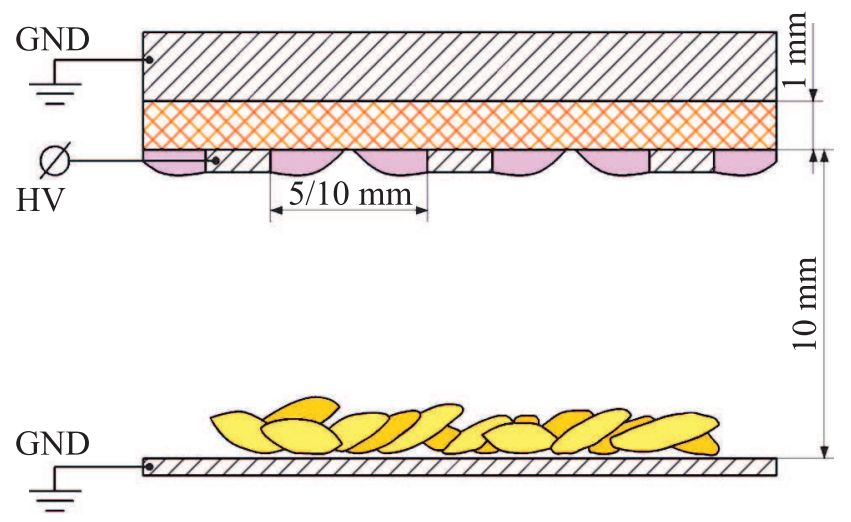

Рис. 1. Схема экспериментальной установки.

В работе [15] показано, что результат (успешность) подобной обработки семян озимой ржи зависит от обстоятельств нагрева электродной конфигурации ПДБР. Для снижения влияния температуры барьера было принято решение использовать относительно невысокую питающую частоту. Электродная система питалась напряжением синусоидальной формы 1.8, 2.1, 2.4 и $2.7 \mathrm{kV}$ действующего с частотой $4.4 \mathrm{kHz}$. Семена экспонировались $10,60,120$ и $180 \mathrm{~s}$.

После обработки семена закладывались на проращивание без выдержки. Проращивались трое суток в темноте на дистиллированной воде на двух слоях фильтровальной бумаги в термостате при $24 \pm 1^{\circ} \mathrm{C}$. Начальное увлажнение - $6 \mathrm{ml}$ на вариант, ежесуточное $-2 \mathrm{ml}$ на вариант. Все эксперименты по проращиванию выполнены с июля по октябрь 2019 г. По завершении проращивания контролировалась длина побега, длина индивидуальных корней и трехсуточная всхожесть (энергия прорастания). Число проростков, проанализированных на вариант, по совокупности экспериментов от 300 до 500.

Для визуализации течения в зазоре между плоскостью диэлектрического барьера и заземленной плоскостью использовался метод трассерной визуализации частиц (PIV). Поток засеивался частицами масла с характерным размером $1-2 \mu \mathrm{m}$. Частицы подсвечивались лазером в плоскости, перпендикулярной кромкам полосовых электродов ПДБР. Скорость в точке определялась с помощью кросс-корреляционной обработки пар изображений, снятых с задержкой порядка $10 \mu \mathrm{s}$. Для построения конечных полей скорости использовалось осреднение по 70 мгновенным измерениям. Визуализация течения в зазоре проводилась без слоя семян на заземленной плоскости.

\section{2. Результаты}

На рис. 2 и 3 приведены результаты восстановления поля скоростей для широких и узких полос соответственно в случаях различных напряжений питания. 


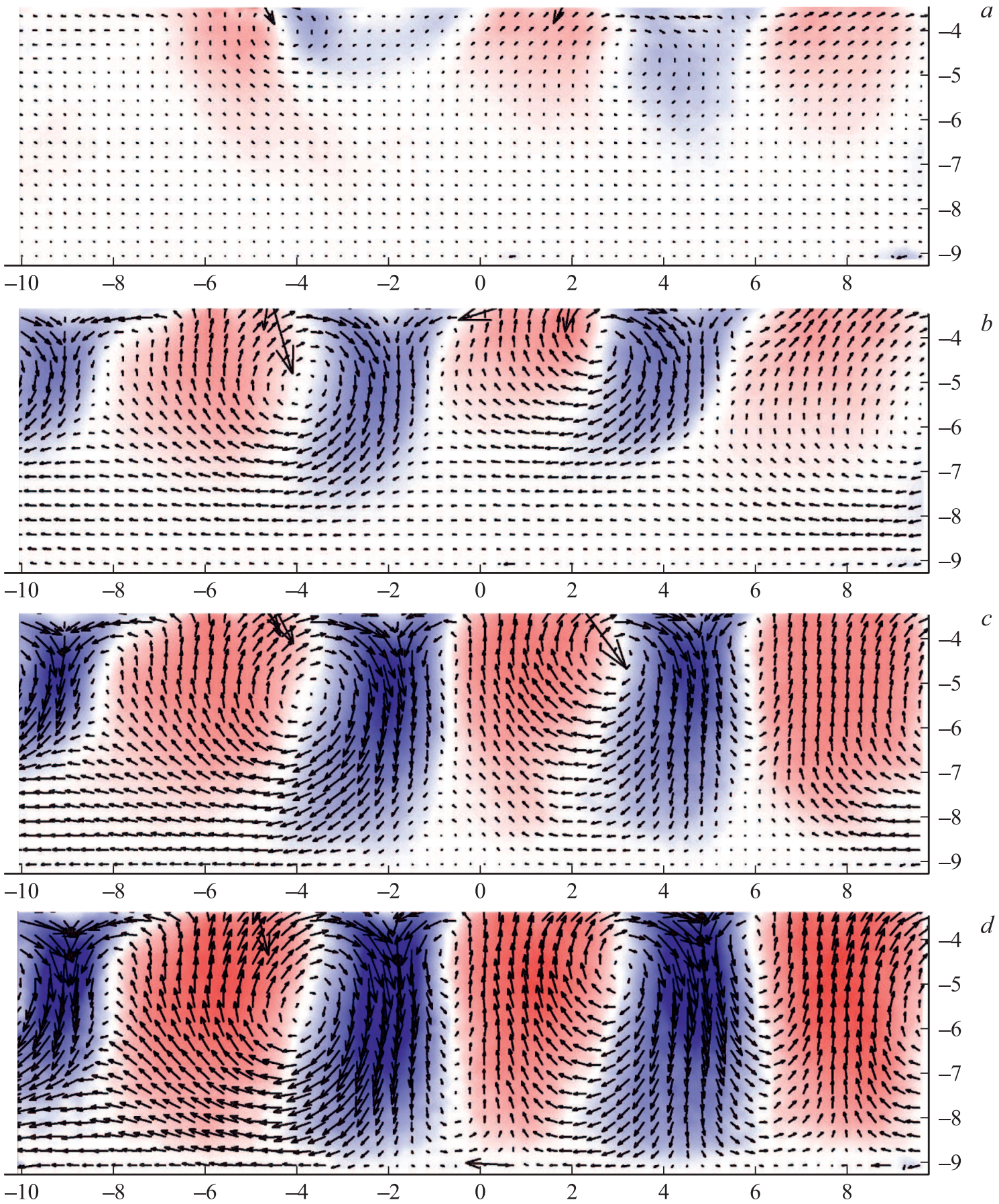

Рис. 2. Структура течения в зазоре между электродной системой ПДБР и заземленной пластиной в случае для широких полос при $1.8(a), 2.1(b), 2.4(c)$ и $2.7 \mathrm{kV}(d)$.

При широких полосах на напряжениях 1.8 и $2.1 \mathrm{kV}$ зона рециркуляции воздушного потока охватывает половину промежутка, а уже $2.4 \mathrm{kV}$ занимает практически весь промежуток, что заметно обостряется на $2.7 \mathrm{kV}$. При узких полосах даже при напряжении $2.7 \mathrm{kV}$ зона рециркуляции не отдаляется от поверхности барьера более чем на расстояние, сравнимое с расстоянием между полосами. Возникают слабые однородные течения, направленные в сторону барьера.
На рис. 4-6 приведены результаты измерения морфологических характеристик проростков из обработанных семян в системах с широкими (10 mm между полосами) и с узкими (5 mm между полосами) полосами.

Реакция по длине побега проходит наиболее ярко. Для случаев 1.8 и $2.1 \mathrm{kV}$ и широких полос наблюдается тенденция к снижению длины побега. Разницы между этими режимами практически нет. Режимы 2.4 и $2.7 \mathrm{kV}$ демонстрируют тенденцию к стимуляции длины побега. 

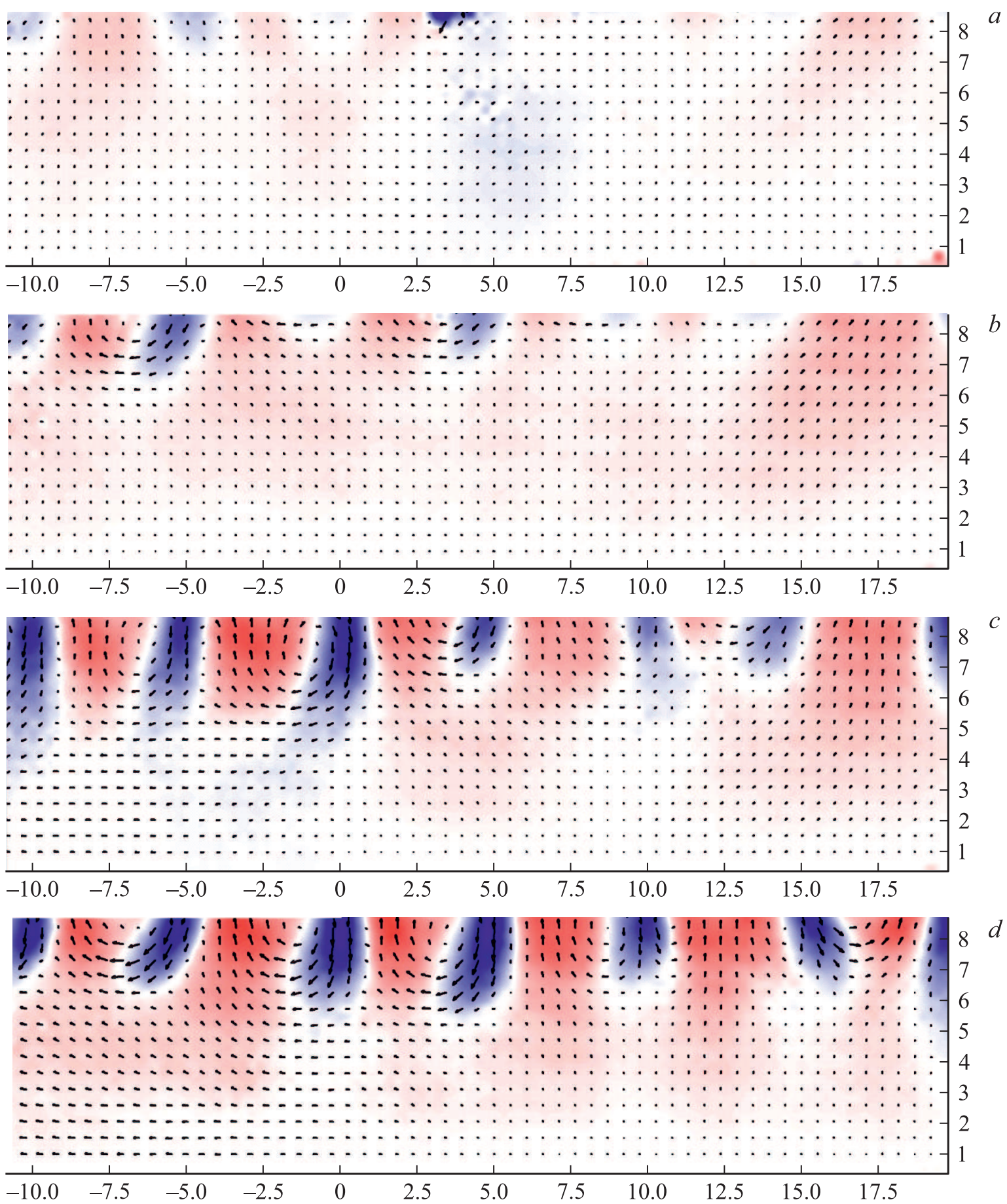

Рис. 3. Структура течения в зазоре между электродной системой ПДБР и заземленной пластиной в случае для узких полос при $1.8(a), 2.1(b), 2.4(c)$ и $2.7 \mathrm{kV}(d)$.

На $60 \mathrm{~s}$ наибольшее влияние имеет $2.7 \mathrm{kV}$. На $180 \mathrm{~s}$ наибольшее влияние имеет $2.4 \mathrm{kV}$. На этих же режимах наблюдается аналогичная по значимости реакция корневой системы. В случае узких полос не наблюдается режимов, в которых демонстрируется тенденция к увеличению длины побега или корневой системы. При этом наблюдается заметное ингибирование длин побега в режимах $2.7 \mathrm{kV}$. Число нормально проросших семян не меняется под действием обработки как в случаях широких, так и узких полос.

\section{3. Обсуждение}

Всхожесть семян не изменяется, следовательно, влияние обработки на морфологию не формируется че- 

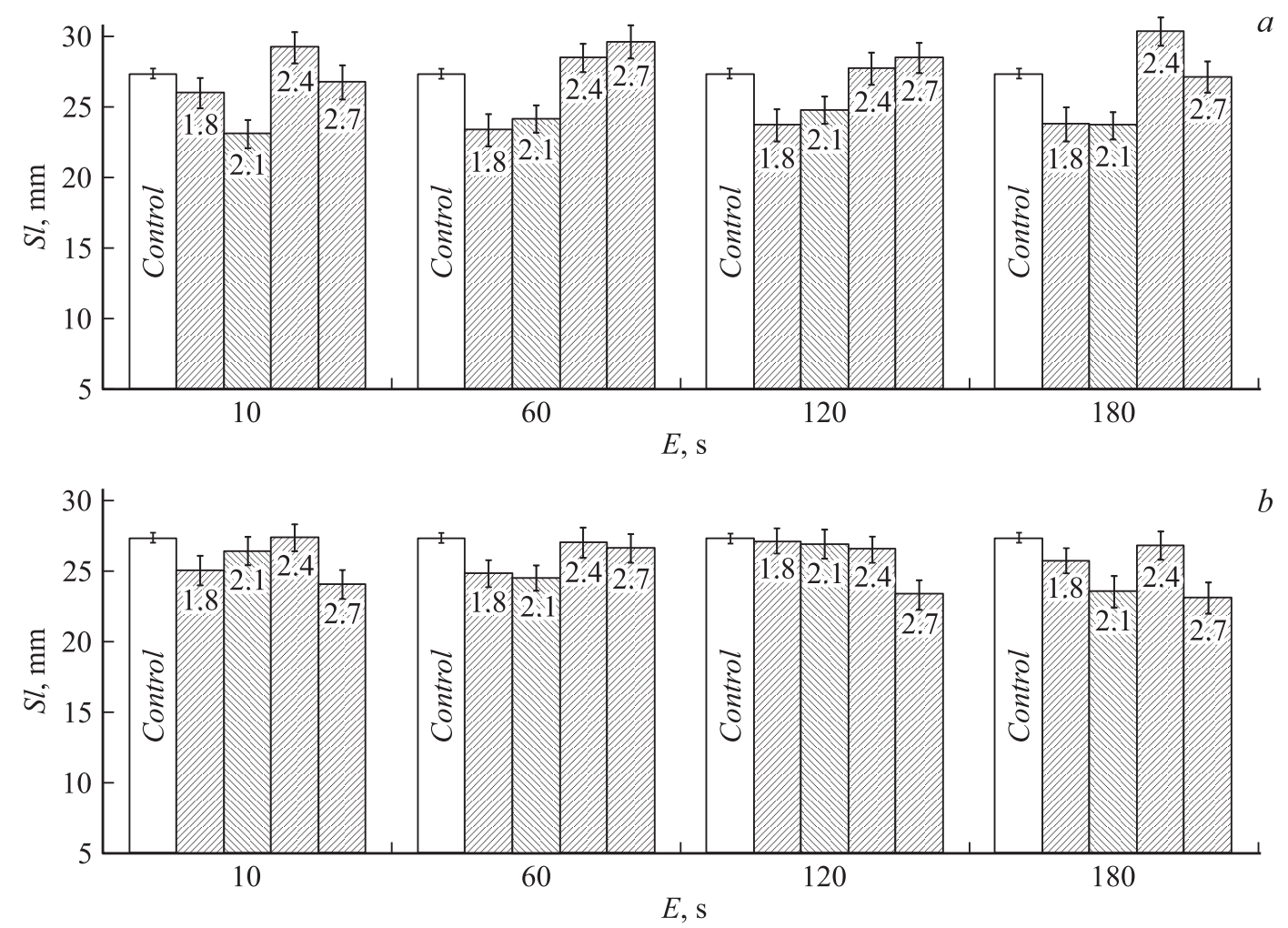

Рис. 4. Длина побега $(S l)$ в зависимости от времени экспозиции $(E)$ и напряжения на электродах для случаев широких $(a)$ и узких (b) полос.
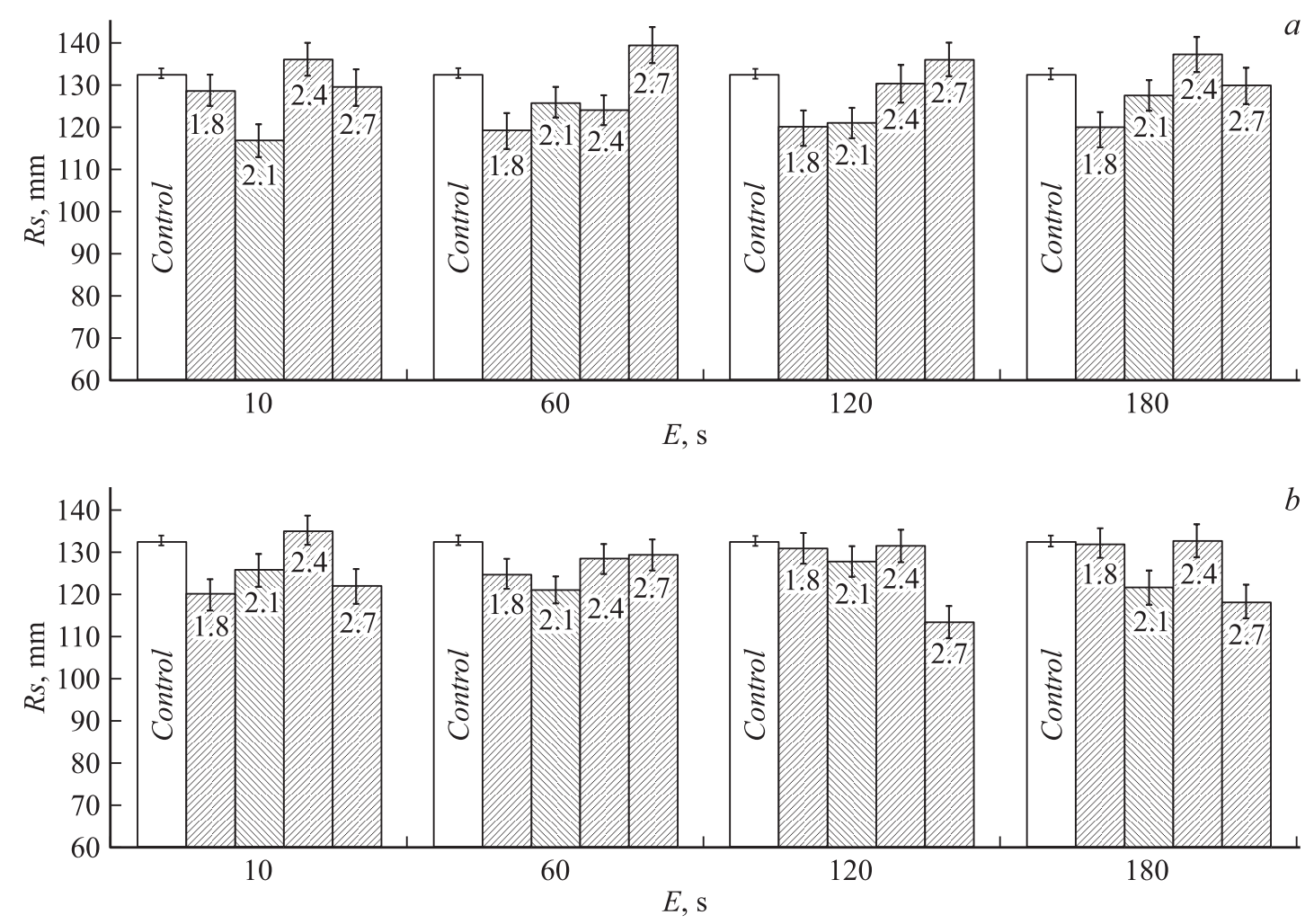

Рис. 5. Суммарная длина индивидуальных корней $\left(R_{s}\right)$ в зависимости от времени экспозиции $(E)$ и напряжения на электродах для случаев широких $(a)$ и узких $(b)$ полос. 

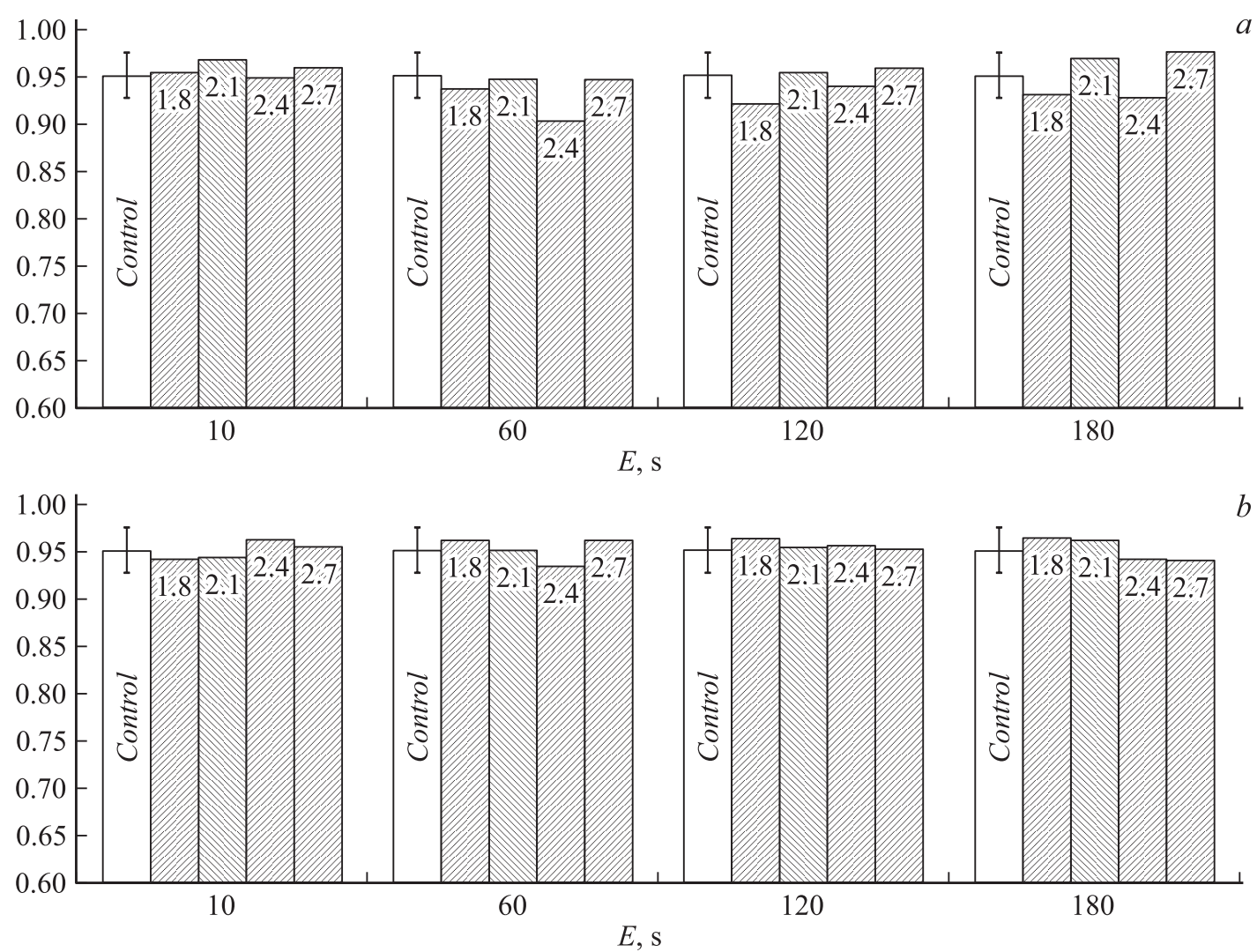

Рис. 6. Доля нормально проросших на третьи сутки семян в зависимости от времени экспозиции и напряжения на электродах для случаев широких $(a)$ и узких $(b)$ полос.

рез уничтожение (выведение из подсчета статистики) слабых проростков или через преодоление состояния физиологического покоя отдельных нормально не прорастающих семян (обратный эффект — „введение“ слабых проростков). В подавляющем большинстве случаев ответ проростка не органоспецифичен. Стимуляция или ингибирование по побегу сопровождается аналогичным эффектом по длине корней. Для широких полос, по сравнению поля скоростей, существуют только два различающихся режима. Это $1.8-2.1 \mathrm{kV}$, когда зона рециркуляции не охватывает плоскость, и $2.4-2.7 \mathrm{kV}$, когда зона рециркуляции проходит по плоскости. Это отражается в ответе морфологических характеристик. В случаях экспозиций 60 и $120 \mathrm{~s}$ также наблюдается зависимость эффекта от напряжения. В электродной конфигурации с узкими полосами, как было отмечено, зона рециркуляции даже при напряжении $2.7 \mathrm{kV}$ не охватывает более половины промежутка. Режимы по напряжению в этом случае практически не отличаются, если наблюдаются тенденции, то они имеют ингибирующий характер. Режимы 1.8 и $2.1 \mathrm{kV}$ на узких полосах не отличаются от аналогичных режимов на широких полосах.

\section{Заключение}

Обстоятельства обработки семян продуктами плазмы ПДБР напрямую связаны с обстоятельствами распреде- ления ионного ветра в промежутке между диэлектрическим барьером и заземленной плоскостью. Вероятно, обострить действие ионного ветра можно с помощью наложения напряжения смещения на плоскость, на которой расположены семена. Это предполагается исследовать в дальнейших работах.

\section{Финансирование работы}

Исследование выполнено за счет гранта Российского научного фонда (проект № 18-76-10019).

\section{Конфликт интересов}

Авторы заявляют, что у них нет конфликта интересов.

\section{Список литературы}

[1] Городецкая E.A. // Научный журнал „Известия КГТУ““. 2016. № 40. C. 1-8.

[2] Rifna E.J., Ratish Ramanan K., Mahendran R. // Trends Food Sci. Technol. 2019. Vol. 86. P. 95-108. https://doi.org/10.1016/j.tifs.2019.02.029

[3] Araújo S.S., Paparella S., Dondi D., Bentivoglio A., Carbonera D., Balestrazzi A. // Front. Plant Sci. 2016. Vol. 7. P. 646. DOI: $10.3389 /$ fpls.2016.00646 
[4] Гордеев Ю.А. Методологические и агробиологические основы предпосевной биоактивации семян сельскохозяйственных культур потоком низкотемпературной плазмы. Автореферат дисс. Смоленск, 2012. 46 с.

[5] Повышение урожайности концентрированным светом / Под общ. ред. проф. А.А. Шахова. М.: Колос, 1972. 399 с.

[6] Lazukin A., Chernyshev T., Krivoruchko D. // Phys. Plasmas. 2019. Vol. 26. P. 033513. https://doi.org/10.1063/1.5083182

[7] Zhang B., Li R., Yan J. // Archives of Biochemistry and Biophysics. 2018. Vol. 655. P. 37-42. https://doi.org/10.1016/j.abb.2018.08.004

[8] Zahoranová A., Hoppanová L., Šimončicová J., Tučeková Z., Medvecká V., Hudecová D., Kaliňáková B., Kováčik D., Černák M. // Plasma Chem. Plasma Process. 2018. Vol. 38. P. 969-988. https://doi.org/10.1007/s11090-018-9913-3

[9] Korakotchakorn H., Poolyarat N., Chittapun S., Amnuaysin N. // Songklanakarin. J. Sci. Technol. 2018. Vol. 40. N 4. P. 819-823.

[10] Sakiyama Y., Graves D.B. // Plasma Sources Sci. Technol. 2013. Vol. 22. P. 012003. https://doi.org/10.1088/09630252/22/1/012003

[11] Sakiyama Y., Graves D.B., Chang H., Shimizu T., Morfill G. // J. Phys. D: Appl. Phys. 2012. Vol. 45. N 42. P. 425201. https://doi.org/10.1088/0022-3727/45/42/425201

[12] Nassour K., Brahami M., Tilmatine A., Nemmich S., Miloua F., Ramdani N., Zouzou N. // IEEE Transactions on Dielectrics and Electrical Insulation. 2018. Vol. 25. N 2. P. 428-434. DOI: 10.1109/TDEI.2017.006600

[13] Avdeeva V., Zorina E., Bezgina J., Kolosova O. // 17th International Sci. Conf. Eng. Rural Development. 2018. Jelgava. P. 543-546. DOI: 10.22616/ERDev2018.17.N128

[14] Dickenson A., Morabit Y., Hasan M.I., Walsh J.L. // Sci. Rep. 2017. Vol. 7 (1). P. 14003. DOI: 10.1038/s41598-017-14117-1

[15] Lazukin A.V., Serdyukov Y.A., Moralev I.A., Selivonin I.V., Krivov S.A. // J. Phys.: Conf. Ser. 2019. Vol. 1147. P. 012124. DOI: $10.1088 / 1742-6596 / 1147 / 1 / 012124$ 